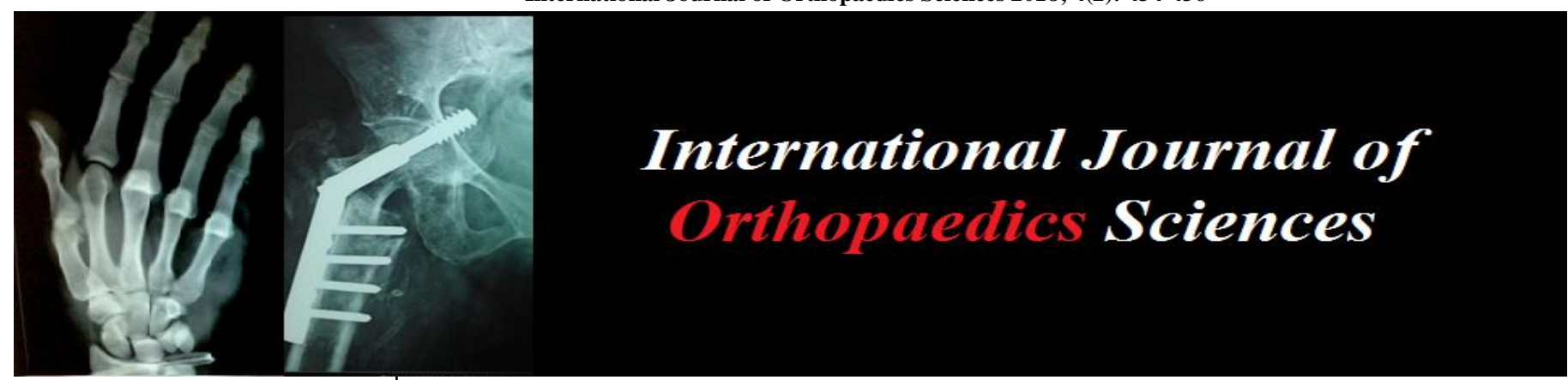

ISSN: $2395-1958$

IJOS 2018; 4(2): 434-436

(C) 2018 IJOS

www.orthopaper.com

Received: 22-02-2018

Accepted: 25-03-2018

Dr. Giridhar Boyapati MS (Ortho), FIJR, Maxcure hospitals, Hitech city,

Hyderabad, Telangana, India
Correspondence

Dr. Giridhar Boyapati

MS (Ortho), FIJR, Maxcure

hospitals, Hitech city,

Hyderabad, Telangana, India

\section{Aneurysmal bone cyst of tibia shaft: A rare case report}

\section{Dr. Giridhar Boyapati}

DOI: https://doi.org/10.22271/ortho.2018.v4.i2g.68

\section{Abstract}

Aneurysmal bone cyst is a pseudotumoral lesion of unknown etiology accounting for $1 \%$ of bone tumours. They are locally destructive, blood filled lesions commonly effecting proximal humerus, distal femur and proximal tibia. Most often eccentrically located in the metaphysis. Diaphysis involvement is very rare. Very few cases of aneurysmal bone cyst of tibia shaft have been reported in literature. We report a case of 14 year old girl complaining of pain and swelling left leg with a diagnostic dilemma between Aneurysmal bone cyst of tibia diaphysis and Telengectatic osteosarcoma. ABC was confirmed with MRI and biopsy. The patient was surgically treated by curettage and bone grafting along with reconstruction of the tibia by using contralateral fibula strut graft. At the 1-year follow-up, the patient responded favourably to this form of treatment and lesion healed well.

Keywords: Aneurysmal bone, a rare case report

\section{Introduction}

Any bone may be affected by $\mathrm{ABC}$, however, these lesions predominantly manifest in the metaphysis of long bones $(65 \%)$, the pelvis $(12 \%)$ and the arch of the spine $(12 \%)^{[1]}$. ABC involves asymmetrically the metaphyseal area of a long bone and does not invade the epiphysis if the epiphyseal line is intact ${ }^{[2]}$. It rarely involves diaphysis of long bones. The present study reports a case of $\mathrm{ABC}$ localised to the shaft of tibia, a considerably rare presentation of which only a few cases have been reported to date.

\section{Case Report}

A 14 year old female presented with complaints of pain and swelling of right leg since 4 months with no history of trauma. Swelling was gradually increasing in size. On examination swelling of size $10 * 5 \mathrm{~cm}$ over the proximal tibial shaft. Skin over the swelling is normal, no scars and discharging sinuses. Soft to firm cystic swelling, slightly tender with no local rise of temperature. Movements at knee and ankle joint were normal. Standard radiographs of the right leg anterioposterior and lateral views were performed. X-rays showing expansile eccentric lytic lesion with thin internal septations noted in diaphysis of tibia. Cortex was thin with adjacent soft tissue swelling. From the $\mathrm{x}$-ray findings the differential diagnosis of ABC and Telangectatic osteosarcoma were made. MRI was done which is more suggestive of ABC. Patient was advised operative management. Extended curettage, fibular grafting and plating was done. Using a extended anterolateral approach to tibia, Tibialis anterior is subperiosteally elevated, lesion is exposed curettage done. After curettage only anteromedial cortex of tibia is left intact. Fibular graft from contralateral leg was used to reinforce the tibia and fixed using 10 holed Narrow DCP. Post operatively skin incision healed well. Biopsy report confirmed the diagnosis of $\mathrm{ABC}$

\section{Discussion}

Jaffe and Lichtenstein first described the $\mathrm{ABC}$ as a distinct pathologic lesion in 1942 [3] Although the pathogenesis of $\mathrm{ABC}$ is still unknown, there exists 2 broad types: a primary type without preexisting or coexisting lesion $(70 \%)$ and a secondary form associated with a preexisting lesion (30\%). The most common of these associated lesions include giant-cell tumor, chondroblas- toma, osteoblastoma, chondromyxoid fibroma, osteosarcoma, and fibrous dysplasia $^{[1]}$. 
Radiographs typically show an eccentric, lytic lesion with an expanded, remodelled 'blown out' or 'ballooned' bony contour of the host bone $[4,5]$. The natural history of aneurysmal bone cyst has been described as evolving through four radiological stages: initial, active, stabilization and healing ${ }^{[6]}$.

Computed tomography and MRI scans may be helpful in the diagnosis of $\mathrm{ABC}$, since T2-weighted MRI could detect a deformity in the involved metatarsal bone as a segmented, expansile, multiseptated lesion with a large quantity of fluid present ${ }^{[7]}$. Bone scintigraphy will show increased uptake of radionuclide in all cases and it accurately reflects the extent of osseous involvement in approximately $88 \%$ cases ${ }^{[8]}$.

Biopsy is necessary to confirm the diagnosis of primary $\mathrm{ABC}$ and to exclude an adjacent tumor. The histological pattern of $\mathrm{ABC}$ demonstrates thin cortices, blood elements in the central portion, benign-appearing macrophages, lymphocytes, fibroblasts, bone-forming cells, and giant cells. Surgical removal is considered the optimal treatment option for ABC. Curettage with bone grafting and bone graft substitute remains the gold standard in the treatment of aneurysmal bone cysts. The lesion is removed by intralesional curettage through a wide cortical window, and allograft bone grafting may be used for replacement of bone defects [9]. Embolotherapy has also been successfully used for the treatment of ABCs.
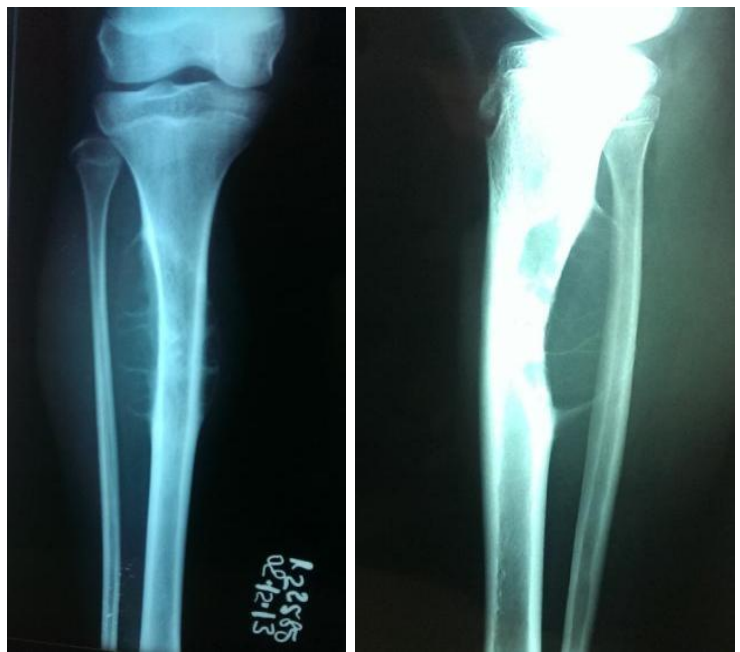

Fig 1: standard radiograph of right leg AP and Lateral views
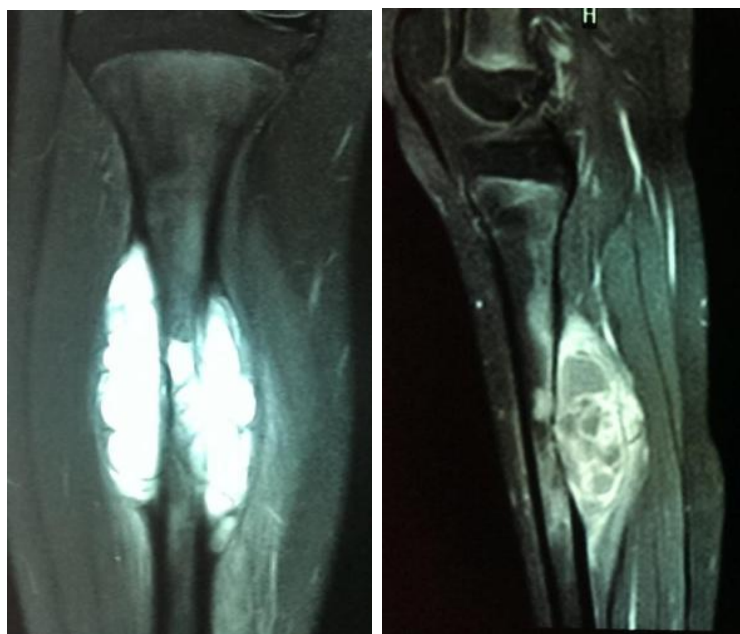

Fig 2: MRI right leg showing expansile lesion located eccentrically \& most posteriorly in proximal half of right tibia measuring $9 \mathrm{~cm} \times 5 \mathrm{~cm} \times 4 \mathrm{~cm}$. esion is multiseptated and multiloculated
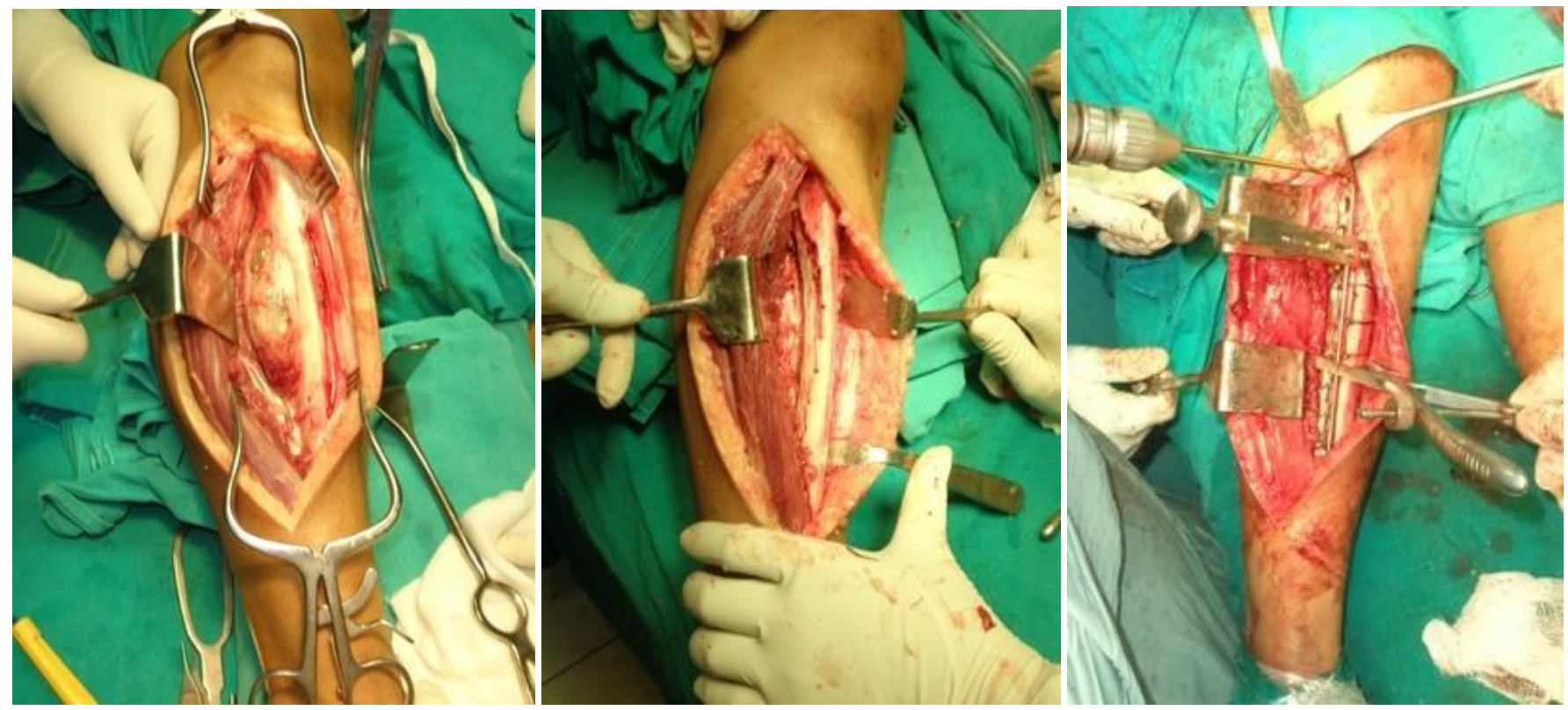

Fig 3: Showing the lesion of tibia shaft before and after curettage leaving only the anteromedial cortex intact. 

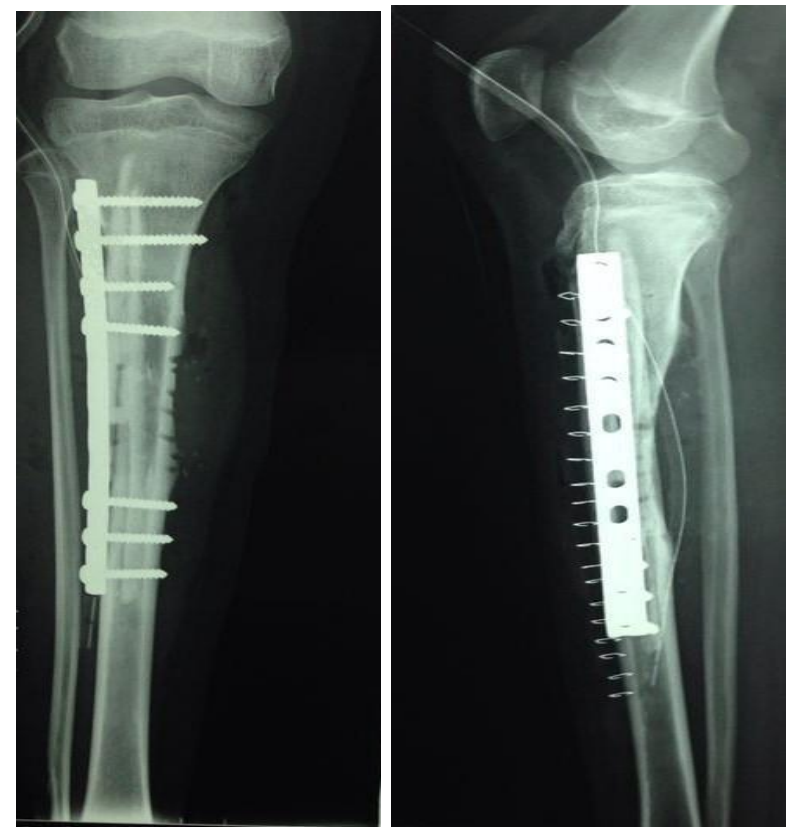

Fig 4: showing the lesion after fibular grafting from opposite leg and fixation with 10 holed DCP and srews. Post operative xray showing tibia reinforced with fibular grafting and plating.

\section{References}

1. Campanacci M, Capanna R, Picci P. Unicameral and aneurysmal bone cysts. Clin Orthop Relat Res. 1986; 204:25-36.

2. Donaldson WF. Aneurysmal bone cyst. J Bone Joint Surg. 1962; 44-A:25-40.

3. Jaffe HL, Lichtenstein L. Solitar y unicameral bone cyst: With emphasis on the roentgen picture, the pathologic appearance, and the pathogenesis. Arch Surg. 1942; 44:1004-25.

4. Hudson TM. Fluid levels in aneurismal bone cysts: $\mathrm{A} \mathrm{Ct}$ feature. AJR. 1984; 141:1001-1004.

5. Scully SP, Temple HT, O'Keefe RJ, Gebhardt MC. Case report 830. Aneursymal bone cyst. Skeletal Radiol. 1994; 23:157-160.

6. Dabska M, Buraczewski J. Aneurysmal bone cysts: pathology, clinical course and radiological appearance. Cancer. 1969; 23:371-388

7. Iltar S, Alemdaroğlu KB, Karalezli N, Irgit K, Caydere M, Aydoğan NH. A case of an aneurysmal bone cyst of a metatarsal: Review of the differential diagnosis and treatment options. J Foot Ankle Surg. 2009; 48:74-79,

8. Hudson TM. Scintigraphy of aneurysmal bone cyst. AJR. 1984; 142:761-765.

9. Boubbou M, Atarraf K, Chater L, Afifi A, Tizniti S. Aneurysmal bone cyst primary-about eight pediatric cases: Radiological aspects and review of the literature. Pan Afr Med J. 2013; 15:111. 